\title{
Hatay ili soğan alanlarında yabancı otlarla mücadele yöntemleri üzerine araştırmalar
}

\author{
Studies on weed control in onion areas in Hatay province
}

\author{
Hikmet KAYA ${ }^{1}$ iD, ilhan ÜREMiş ${ }^{10}$ \\ ${ }^{1}$ Hatay Mustafa Kemal University, Faculty of Agriculture, Department of Plant Protection, Antakya-Hatay, Turkey.
}

\section{MAKALE BILGISI / ARTICLE INFO}

Makale tarihçesi / Article history:

DOI: $10.37908 /$ mkutbd.616591

Geliş tarihi /Received:22.01.2019

Kabul tarihi/Accepted:14.05.2019

\section{Keywords:}

Onion, weed, chemical control, mechanical control

\footnotetext{
Corresponding author: IIlhan ÜREMiş

$\triangle$ : iuremis@mku.edu.tr
}

\section{ÖZET / ABSTRACT}

\begin{abstract}
Aims: Studies were carried out in Kırıkhan district, Hatay-Turkey in 2015 and 2016, to determine the effects of different herbicides, mechanical control and herbicide + mechanical control on the weeds.

Methods and Results: A randomized complete block design was used with three replications. There were nine treatments (pre-emergence, Pendimethalin $450 \mathrm{~g} / \mathrm{l}(300 \mathrm{ml} / \mathrm{da})$, post-emergence Tepraloxydim $45 \mathrm{~g} / \mathrm{l}$ (100 ml/da), Quizalofop- P-ethyl $50 \mathrm{~g} / \mathrm{l}(100 \mathrm{ml} / \mathrm{da})$, Bentazone $480 \mathrm{~g} / \mathrm{l}(200$ $\mathrm{ml} / \mathrm{da})$, Oxyfluorfen $480 \mathrm{~g} / \mathrm{l}(40 \mathrm{ml} / \mathrm{da})$, Linuron $47.5 \mathrm{~g} / \mathrm{l}(100 \mathrm{ml} / \mathrm{da})$, Linuron $47.5 \mathrm{~g} / \mathrm{l}(100 \mathrm{ml} / \mathrm{da})+$ hand hoeing and only hand hoeing including untreated control for each year.

Conclusions: Hand hoeing + Linuron and only Hand hoeing were the most effective treatments for weed control and onion yield in 2015, 2016 and also for average of 2015-2016.

Significance and Impact of the Study: Control programs of weeds should be made by considering conditions, the weed species and densities of onion fields.
\end{abstract}

Atıf / Citation: Kaya H, Üremiş i (2020) Hatay ili soğan alanlarında yabancı otlarla mücadele yöntemleri üzerine araştırmalar. MKU. Tar. Bil. Derg. 25(1) : 27-35. DOI: 10.37908/mkutbd.616591

\section{GiRiş}

Sofraların baş tacı olan soğan geçmişten günümüze mutfaklarımızın ayrılmaz parçası olup insan hayatı ve beslenmesinde önemli bir yeri bulunmaktadır (Vural ve ark., 2000; Günay, 2005; Yünlü, 2011). Soğan toprak altındaki kısımlarının, yedek besin deposu olarak şişip kalınlaşması suretiyle meydana gelen başları besin maddesi olarak kullanılan bir sebzedir (Kozan, 1997).

Tüm dünyada olduğu gibi soğan üretimi, başta fungal etmenler olmak üzere, bakteriyel ve viral hastalık etmenleri, zararlılar ve yabancı otlar tarafından olumsuz yönde etkilenmektedir (Schwartz ve Mohan, 2008; Soylu ve ark., 2014).

Soğan, oldukça yavaş büyüyen, kısa boylu ve yüzeysel köklü bir bitki olması nedeni ile yabancı otlar ile rekabeti düşüktür, ayrıca silindirik biçimli dikine büyüyen yapraklar toprak üzerinde gölgeleme yapamadıkları için yabancı otların gelişimine zemin hazırlamaktadır
(Klingman ve Ashton, 1982; Özer ve ark., 2001; Kızılkaya ve ark., 2001; Bell ve ark., 2002; Kızılkaya, 2003; Ghosheh, 2004; Carlson ve Kirby, 2005). Ayrica, yabancı otlar sahip oldukları allelopatik etkileriyle de soğanların gelişimini olumsuz etkilemektedir. Soğanın önemli yabancı otlarından birisi olan Sirken (Chenopodium album L.) soğanın çimlenmesini ve gelişimini olumsuz etkilemektedir (Kızılkaya ve ark., 2001; Kızılkaya, 2003). Yabancı otlar ürün kaybının yanında kültürel işlemlerin zamanında ve istenilen etkinlikte yapılmasını engellemekte, zehirli tohumları ürüne karışarak insan ve hayvan sağlığını olumsuz etkilemekte, hastalık ve zararlılara da konukçuluk etmektedirler (Uygur ve ark., 1984; Zimdahl, 2018; Tepe, 2014; Güncan, 2016). Yabancı otlar kültür bitkisi ile büyüme faktörleri yönünden rekabete girerek, kültür bitkisinin gelişmesini engellemekte, yapraklarının küçük olması nedeniyle yabancı otlarla yeterince rekabet edemeyen (Smith ve ark., 2008) soğanın kalite ve veriminin \% 25-60 oranında 
düşmesine neden olmaktadır (Hussain, 1983; Özer ve ark. 2001; Tepe, 2014; Güncan, 2016). Dünyada belli başlı kültür bitkilerinde (buğday, mısır, çeltik, pamuk, soya) zarara neden olan hastalıklar, zararlılar ve yabancı otların neden olduğu ürün kaybı yaklaşık \% 67.15 olup, bunun \% 21.75 'i zararlılardan \% 13.78'i hastalıklardan ve $\%$ 31.62'si ise yabancı otlardan kaynaklanmaktadır (Derke ve ark., 1994). Yabancı otlardan ileri gelen sorunların en aza indirilebilmesi, verimin ve kalitenin arttırılabilmesi için yabancı otlarla etkili bir şekilde mücadelenin gerekliliği ortadadır (Uludağ ve ark., 2018; Kaya ve Üremiş, 2019).

Türkiye'de yapılan çalışmalarda yabancı otların soğan verimini \% $70^{\prime}$ lere varan oranda düşürdüğü bildirilmektedir (Kızılkaya ve ark., 2001; Kızılkaya, 2003; Gürbüz, 2007). Diğer ülkelerde yapılan çalışmalarda ise verim kaybının \% 25-75 arasında olduğu görülmektedir (Babiker ve Ahmed, 1986; Suleman ve Jamal, 2002; Qasem, 2006; Khokhar ve ark., 2006). Soğanda yabancı ot mücadelesi üreticilerin karşılaştıkları en önemli sorunların başında gelmektedir. Karşılaşılan sorunlardan dolayı soğanda seçimi de karşılaşılan en önemli zorluklar arasında bulunmaktadır. Ayrıca, soğan alanlarında yabancı ot mücadelesinde mekanik mücadelenin çok zor, elle yolmanın da hem zor hem de çok masraflı olması (Özer ve ark., 2001; Bell ve ark., 2002; Van Der Weide ve ark., 2008; Tepe, 2014), yabancl ot mücadelesinde kullanılacak herbisitlerin seçimindeki zorluklar nedeniyle bu konuda yeni çalışmalara intiyaç olduğu aşikârdır.

Ülkemiz soğan alanlarında yapılan yabancı otlara yönelik çalışmalar çok sınırlı olup, genellikle Marmara Bölgesi'nde yapılmış ve kullanılan herbisitlerin güncelliği kalmamıştır (Kurçman ve ark., 1983; Özdemir ve ark., 1983).

Çukurova'da soğanda yaptığı yabancı otların mücadelesine yönelik çalışmada yabancı ot mücadelesinde kullanılan karakterlerin soğan verimlerine olan etkilerine bakıldığı zaman en iyi verim yabancı otsuz kontrol parsellerinden $\left(16.2 \mathrm{~kg} / \mathrm{m}^{2}\right)$ elde edilmiş, bu karakteri takiben sırası ile Oxadiazon (11.9 $\left.\mathrm{kg} / \mathrm{m}^{2}\right)$, Oxyfluorfen $\left(11.7 \mathrm{~kg} / \mathrm{m}^{2}\right)$, Pendimethalin $(10.0$ $\left.\mathrm{kg} / \mathrm{m}^{2}\right)$, Tepraloxydim $\left(9.6 \mathrm{~kg} / \mathrm{m}^{2}\right)$ ve yabancı otlu kontrol $\left(9.1 \mathrm{~kg} / \mathrm{m}^{2}\right)$ gelmiştir. Yabancı otların sürekli olarak elle çekilmesi ile yapılan mücadelenin, yabancı otlu parsellere göre \% 76.3'lük verim artışını sağlaması, soğan yetiştiriciliğinde yabancı ot mücadelesinin çok önemli olduğu ortaya konulmuştur (Gürbüz, 2007).

Bu çalışma ile Akdeniz Bölgesi tarımında önemli yeri olan Hatay ili soğan alanlarında bulunan yabancı otlara karşı etkili mücadele yöntemlerinin bulunması amaçlanmıştır. Çalışma sonucunda elde edilen sonuçların "Entegre Mücadele" veri tabanına katkıda bulunacağı ve yabancı otlarla mücadele programlarının geliştirilmesine katkı sağlanacağı beklenmektedir.

\section{MATERYAL ve YÖNTEM}

Soğan alanlarındaki yabancı otlarla mücadele çalışmaları Hatay'ın Kırıkhan ilçesinde yapılmıştır. Burada 2015 yılına ait araştırmalar; Aralık 2014 - Haziran 2015 döneminde Kangallar köyünde, 2016 yılına ait araştırmalar ise Aralık 2015-Haziran 2016 döneminde Özsoğuksu köyünde yürütülmüştür. Amik ovası içerisinde yer almakta olan deneme alanları tipik Akdeniz ikliminin etkisi altındadır. Toprakları killi yapıda olup, hafif alkali karakter göstermektedir. Organik madde içeriği bakımından zayıf olan topraklar az tuzlu ve çok kireçli yapıdadır.

Denemeler Tesadüf Blokları Deneme Desenine göre 9 karakterli ve 3 tekerrürlü olarak kurulmuştur. Çalışmada geçci bir soğan çeşidi olan Hazera çeşidi tohumluk kullanılmıştır. Soğan yetiştiriciliği sırasında yapılan işlemlere ait bazı bilgiler Çizelge 1.'de görülmektedir. Deneme parselleri $6 \mathrm{~m}^{2}(2 \mathrm{~m} \times 3 \mathrm{~m})$ olup, bloklar arasında ve uygulama parselleri arasında 1'er $m$ mesafe (emniyet şeridi) bırakılmıştır. Çalışmada yabancı ot mücadelesi yapılmayan kontrol parselini de içeren 9 uygulama (çıkış öncesi Pendimethalin $450 \mathrm{~g} / \mathrm{l}(300 \mathrm{ml} / \mathrm{da})$, çıkış sonrası Tepraloxydim $45 \mathrm{~g} / \mathrm{l}(100 \mathrm{ml} / \mathrm{da})$, Quizalofop-P-ethyl 50 $\mathrm{g} / \mathrm{l}(100 \mathrm{ml} / \mathrm{da})$, Bentazone $480 \mathrm{~g} / \mathrm{l}(200 \mathrm{ml} / \mathrm{da})$, Oxyfluorfen $480 \mathrm{~g} / \mathrm{l}(40 \mathrm{ml} / \mathrm{da})$, Linuron $47.5 \mathrm{~g} / \mathrm{l}$ (100 $\mathrm{ml} / \mathrm{da})$, Linuron $47.5 \mathrm{~g} / \mathrm{l}(100 \mathrm{ml} / \mathrm{da})+$ Çapası ve Çapa) ele alınmıştır. Çalışmada kullanılan herbisitler sabit basınçlı (3 atm) ve yelpaze hüzmeli memeye (03F110, Lurmark) sahip sırt pülverizatörüyle $20 \mathrm{~L} /$ da ilaçlama normunda, çıkış öncesi Pendimethalin ekimden hemen sonra, çıkış sonrası uygulamalar ise 1. yıl 15 Şubat 2015, 2. yıl ise 17 Şubat 2016 tarihlerinde uygulanmıştır.

Mekanik mücadele için yapılan el çapalarına bakıldığında, her iki yılda da ilk çapalar Mart'ın birinci haftasında, 2. çapalar Nisan'ın birinci haftasında ve 3 . çapalar ise Mayıs'ın ilk haftasında yapılmıştır. Parseller uygulamalardan 7, 14 ve 28 gün sonra değerlendirilmiş olup son kararda 28. gün değerlendirmeleri esas alınmıştır. Ayrıca, her iki yılda da Haziran'ın başında parseller hasat edilmiş olup yapılan uygulamaların etki değerlendirilmelerinde soğanın verim değerleri dikkate alınmıştır. Elde edilen veriler Arcsin transformasyonuna tabi tutulmuştur (Zar,1996). İstatistiki analizler transformasyon uygulanan verilere uygulanmıştır. Sonuçlara SPSS istatistik programında (ANOVA) istatistiki analiz uygulanmış ve ortalamaların karşılaştırılması \% 5 önem düzeyinde Duncan testi ile yapılmış ve gruplandırılmıştır. 


\section{BULGULAR ve TARTIŞMA}

Soğan tarlalarında bulunan yabancı otlara karşı herbisit uygulamaları, mekanik mücadele ve kimyasal + mekanik mücadelenin etkinliklerini belirleme çalışmaları Kırıkhan ilçesinde 2015 ve 2016 yıllarında yapılmıştır. Bu amaçla çıkış öncesi Pendimethalin $450 \mathrm{~g} / \mathrm{l}(300 \mathrm{ml} / \mathrm{da})$, çıkış sonrası Tepraloxydim $45 \mathrm{~g} / \mathrm{l}(100 \mathrm{ml} / \mathrm{da})$, Quizalofop- Pethyl $50 \mathrm{~g} / \mathrm{l}(100 \mathrm{ml} / \mathrm{da})$, Bentazone $480 \mathrm{~g} / \mathrm{l}(200 \mathrm{ml} / \mathrm{da})$, Oxyfluorfen $480 \mathrm{~g} / \mathrm{l}(40 \mathrm{ml} / \mathrm{da})$, Linuron $47.5 \mathrm{~g} / \mathrm{l}(100$ $\mathrm{ml} / \mathrm{da})$, Linuron $47.5 \mathrm{~g} / \mathrm{l}(100 \mathrm{ml} / \mathrm{da})+$ Çapa ve Çapa uygulamaları yapılmıştır. Buradan elde edilen sonuçlar yabancı ot mücadelesi yapılmayan Kontrol parselleri ile karşılaştırılmıştır. Ayrıca, uygulamaların soğan verimine etkileri hesaplanmıştır. Çalışmada kontrol parselinde saptanan hakim yabancı ot türleri; Anagallis arvensis L. (ANAAR), Anthemis arvensis L. (ANTAR), Capsella bursa pastoris (L.) Medik. (CAPBU), Chenopodium album L. (CHEAL), Lamium amplexicaule L. (LAMAM), Raphanus raphanistrum L. (RAPRA), Sinapis arvensis L. (SINAR), Silybum marianum (L.) Gaertner (SILMA), Sonchus oleraceus L. (SONOL), Stellaria media (L.) Media (STEMA), Veronica hederifolia L. (VERHE), Alopecurus myosuroides Hudson (ALOMY), Avena sterilis L. (AVEST), Phlaris brachystachys L.(PHABR), kendi gelen buğday (KENBU)'dır. Çalışmaların yapıldığı 2015, 2016 yılları ve iki yılın ortalama sonuçlarına göre (Çizelge 2., Çizelge 3. ve Çizelge 4.) sırasıyla;

Pendimethalin $450 \mathrm{~g} / \mathrm{l}$, SINAR (\% 90.3 $\pm 4.2, \% 90.7 \pm 2.9$ ve $\% 90.5 \pm 1.3$ ), ANAAR (\% 90.0 $\pm 2.6, \% 90.0 \pm 1.2$ ve \% $90.2 \pm 1.6$ ), CAPBU (\% $90.7 \pm 3.0, \% 90.0 \pm 2.7$ ve $\%$ $90.3 \pm 1.4)$ ve KENBU (\% 95.3 $\pm 2.9, \% 90.7 \pm 4.3$ ve \% 93.0 \pm 2.5$)^{\prime}$ ya karşı \% 90'ın üzerinde etki göstermiştir. SONOL $\quad(\% 85.3 \pm 2.9, \% 85.0 \pm 2.9$ ve \% 85.2 \pm 2.9 ), CHEAL (\% 85.3 \pm 2.9 , \% 80.3 \pm 3.2 ve \% $82.8 \pm 2.7$ ), VERHE (\% $90.3 \pm 2.9, \% 82.7 \pm 3.9$ ve $\%$ $86.5 \pm 2.0$ ), LAMAM (\% $85.3 \pm 2.9$, \% $86.0 \pm 3.1$ ve \% $85.7 \pm 2.9$ ), STEME (\% $90.3 \pm 0.3, \% 84.7 \pm 3.5$ ve $\%$ $87.5 \pm 1.8$ ), SLYMA (\% $80.3 \pm 4.8, \% \quad 81.7 \pm 3.3$ ve $\%$ $81.0 \pm 0.8$ ), ANTAR (\% $81.0 \pm 3.8, \% 80.0 \pm 2.9$ ve $\%$ $80.5 \pm 2.8$ ), RAPRA (\% $85.7 \pm 2.3, \% 76.7 \pm 4.4$ ve $\%$ $81.2 \pm 3.2$ ), AVEST (\% 90.3 $\pm 2.9, \% 83.3 \pm 4.4$ ve $\% 86.8 \pm 1.9$ ) ve ALOMY (\% 90.7 $\pm 0.7, \% 84.3 \pm 2.3$ ve $\%$ $87.5 \pm 1.3$ 'ye karşı \% 80'in üzerinde etki göstermiştir. PHABR (\% 80.3 $\pm 7.7, \% 71.7 \pm 3.3$ ve \% 76.0 \pm 5.6 )'ya ise her iki yılda ve iki yılın ortalamasında karşı \% 70'in üzerine etki göstermiştir.

Tepraloxydim $45 \mathrm{~g} / \mathrm{l}$, AVEST (\% 91.3 \pm 2.1 , $\% 95.7 \pm 2.3$ ve $\%$ 93.5 \pm 1.8 ), ALOMY (\% 93.3 \pm 4.5 , \% 90.3 \pm 0.3 ve \% $91.8 \pm 2.3)$ ve KENBU

(\% 95.3 $\pm 4.7, \% 95.3 \pm 2.9$ ve $\% 95.3 \pm 2.6$ )'ya her iki yılda ve iki yılın ortalamasında karşı $\% 90$ 'ın üzerine etki gösterirken PHABR (\% 85.7 \pm 3.5 , \% $80.3 \pm 3.2$ ve \% 83.0 1.6 )'a karşı \% 80.0 - \% 86.0 arasında etkili bulunmuştur.

Çizelge 1. Soğan yetiştiriciliğinde yapılan işlemler ve dönemi

\begin{tabular}{|c|c|c|}
\hline Yapılan Uygulamalar & Birinci Yıl (2014-2015) & İkinci Yıl (2015-2016) \\
\hline Goble diskle sürüm (4 defa farklı yönde) & 15 Kasım 2014 & 17 Kasım 2015 \\
\hline Taban gübreleme (18-46, 15 kg/da) & 25 Kasım 2014 & 20 Kasım 2015 \\
\hline Ekim Makinası ile ekim (Hazera çeşidi, 1 kg/da) & 1 Aralık 2014 & 4 Aralık 2015 \\
\hline Yağmurlama & 7 Ocak 2015 & 12 Ocak 2016 \\
\hline $\begin{array}{l}\text { Soğan psyllidi mücadelesi } \\
\text { (Chlorpyrifos ethyl } 480 \mathrm{~g} / \mathrm{l}, 100 \mathrm{ml} / \mathrm{da} \text { ) }\end{array}$ & 17 Şubat 2015 & 20 Şubat 2016 \\
\hline Üst gübreleme (Amonyum nitrat 12 kg/da) & 26 Şubat 2015 & 27 Şubat 2016 \\
\hline Yağmurlama & 26 Şubat 2015 & 28 Şubat 2016 \\
\hline $\begin{array}{l}\text { Üst gübreleme (Amonyum nitrat } 5 \mathrm{~kg} / \mathrm{da}+\text { Amonyum sülfat } \\
5 \mathrm{~kg} / \mathrm{da} \text { ) }\end{array}$ & 16 Mart 2015 & 9 Mart 2016 \\
\hline Üst gübreleme (Amonyum sülfat 15 kg/da) & 3 Nisan 2015 & 7 Nisan 2016 \\
\hline Yağmurlama & 3 Nisan 2015 & 8 Nisan 2016 \\
\hline Fungusit uygulama (Mancozeb \% 80, $200 \mathrm{~g} / \mathrm{da}$ ) & 17 Nisan 2015 & 11Nisan 2016 \\
\hline $\begin{array}{l}\text { Insektisit uygulama } \\
\text { (Malathion } 650 \mathrm{~g} / \mathrm{l}, 150 \mathrm{ml} / \mathrm{da} \text { ) }\end{array}$ & 22 Nisan 2015 & 19 Nisan 2016 \\
\hline $\begin{array}{l}\text { Fungusit + Insektisit } \\
\text { (Mancozeb \% 80, } 200 \mathrm{~g} / \mathrm{da}+ \\
\text { Malathion } 650 \mathrm{~g} / \mathrm{l} 150 \mathrm{ml} / \mathrm{da} \text { ) }\end{array}$ & 6 Mayıs 2015 & 3 Mayıs 2016 \\
\hline Yağmurlama & 7 Mayıs 2015 & 4 Mayıs 2016 \\
\hline Yağmurlama & 23 Mayıs 2015 & 20 Mayıs 2016 \\
\hline Hasat & 5 Haziran 2015 & 9 Haziran 2016 \\
\hline
\end{tabular}


Çizelge 2. Hatay soğan alanlarında yabancı ot mücadele yöntemlerinin etkileri (\%) (2015)

\begin{tabular}{|c|c|c|c|c|c|c|c|c|}
\hline \multirow[t]{2}{*}{ Yabancı Otlar } & \multicolumn{8}{|c|}{ Uygulamalar } \\
\hline & TEP & QUI & PEN & OXY & BEN & LiN & ÇAPA & ÇAPA+LIN \\
\hline \multirow[t]{2}{*}{ ANAAR } & $\mathrm{c}^{*}$ & c & $\mathrm{b}$ & $a b$ & $a b$ & $b$ & $a b$ & $\mathrm{a}$ \\
\hline & $0 \pm 0$ & $0 \pm 0$ & $90.3 \pm 2.6$ & $96.7 \pm 1.7$ & $95.3 \pm 2.9$ & $90.3 \pm 2.6$ & $95.3 \pm 2.9$ & $100 \pm 0$ \\
\hline \multirow[t]{2}{*}{ ANTAR } & e & e & bc & $\mathrm{cd}$ & $d$ & $b$ & a & a \\
\hline & $0 \pm 0$ & $0 \pm 0$ & $81.0 \pm 3.8$ & $75.0 \pm 2.9$ & $71.7 \pm 6.0$ & $85.0 \pm 2.9$ & $100 \pm 0$ & $100 \pm 0$ \\
\hline \multirow[t]{2}{*}{ CAPBU } & c & c & $b$ & $b$ & $a b$ & $b$ & a & a \\
\hline & $0 \pm 0$ & $0 \pm 0$ & $90.7 \pm 3.0$ & $90.3 \pm 2.9$ & $95.3 \pm 0.4$ & $91.3 \pm 2.0$ & $100 \pm 0$ & $100 \pm 0$ \\
\hline \multirow[t]{2}{*}{ CHEAL } & c & c & $b$ & $b$ & $a b$ & $b$ & $a b$ & a \\
\hline & $0 \pm 0$ & $0 \pm 0$ & $85.3 \pm 2.9$ & $85.3 \pm 4.8$ & $90.3 \pm 2.6$ & $85.7 \pm 3.5$ & $92.7 \pm 1.5$ & $95.3 \pm 2.9$ \\
\hline \multirow[t]{2}{*}{ LAMAM } & $c$ & $c$ & $b$ & $\mathrm{a}$ & $\mathrm{a}$ & $\mathrm{a}$ & $\mathrm{a}$ & $\mathrm{a}$ \\
\hline & $0 \pm 0$ & $0 \pm 0$ & $85.3 \pm 2.9$ & $90.7 \pm 2.3$ & $90.3 \pm 1.5$ & $90.3 \pm 1.2$ & $95.0 \pm 2.9$ & $95.3 \pm 2.6$ \\
\hline \multirow[t]{2}{*}{ RAPRA } & $\mathrm{d}$ & $d$ & $b$ & C & c & $b$ & a & a \\
\hline & $0 \pm 0$ & $0 \pm 0$ & $85.7 \pm 2.3$ & $75.7 \pm 4.6$ & $71.7 \pm 3.3$ & $85.0 \pm 5.0$ & $100 \pm 0$ & $100 \pm 0$ \\
\hline \multirow[t]{2}{*}{ SINAR } & c & c & $a b$ & $b$ & $a b$ & $a b$ & a & a \\
\hline & $0 \pm 0$ & $0 \pm 0$ & $90.3 \pm 4.2$ & $80.7 \pm 6.4$ & $90.3 \pm 2.2$ & $90.3 \pm 3.2$ & $95.3 \pm 2.9$ & $94.7 \pm 3.5$ \\
\hline \multirow[t]{2}{*}{ SLYMA } & $d$ & $d$ & $b$ & C & $a b$ & $b$ & a & $a b$ \\
\hline & $0 \pm 0$ & $0 \pm 0$ & $80.3 \pm 4.8$ & $65.0 \pm 5.1$ & $86.3 \pm 3.3$ & $81.0 \pm 3.8$ & $91.7 \pm 1.7$ & $90.0 \pm 2.7$ \\
\hline \multirow[t]{2}{*}{ SONOL } & c & $c$ & $b$ & $a b$ & $\mathrm{a}$ & $b$ & $a b$ & $a b$ \\
\hline & $0 \pm 0$ & $0 \pm 0$ & $85.3 \pm 2.9$ & $90.3 \pm 2.8$ & $95.3 \pm 2.9$ & $85.3 \pm 2.6$ & $90.7 \pm 2.6$ & $91.3 \pm 2.4$ \\
\hline \multirow[t]{2}{*}{ STEME } & $\mathrm{d}$ & $d$ & $b$ & $c$ & $b$ & $b$ & a & a \\
\hline & $0 \pm 0$ & $0 \pm 0$ & $90.3 \pm 0.3$ & $70.7 \pm 3.5$ & $90.3 \pm 0.3$ & $85.3 \pm 5.2$ & $100 \pm 0$ & $100 \pm 0$ \\
\hline \multirow[t]{2}{*}{ VERHE } & c & C & $b$ & $a$ & a & a & a & $a$ \\
\hline & $0 \pm 0$ & $0 \pm 0$ & $90.3 \pm 2.9$ & $95.3 \pm 1.5$ & $95.3 \pm 2.9$ & $95.3 \pm 0.3$ & $100 \pm 0$ & $100 \pm 0$ \\
\hline \multirow[t]{2}{*}{ ALOMY } & $a$ & $a$ & $a$ & $b$ & $b$ & $b$ & a & a \\
\hline & $93.3 \pm 4.5$ & $90.7 \pm 3.4$ & $90.7 \pm 0.7$ & $0 \pm 0$ & $0 \pm 0$ & $0 \pm 0$ & $91.7 \pm 4.4$ & $95.7 \pm 2.3$ \\
\hline \multirow[t]{2}{*}{ AVEST } & $a$ & $a$ & $a$ & $b$ & $b$ & $b$ & a & a \\
\hline & $91.3 \pm 2.1$ & $95.3 \pm 2.9$ & $90.3 \pm 2.9$ & $0 \pm 0$ & $0 \pm 0$ & $0 \pm 0$ & $95.3 \pm 3.7$ & $90.7 \pm 2.9$ \\
\hline \multirow[t]{2}{*}{ PHABR } & $\mathrm{a}$ & $a$ & $a$ & $b$ & $b$ & $b$ & a & $a$ \\
\hline & $85.7 \pm 3.5$ & $81.7 \pm 6.0$ & $80.3 \pm 7.7$ & $0 \pm 0$ & $0 \pm 0$ & $0 \pm 0$ & $95.3 \pm 2.6$ & $90.3 \pm 1.5$ \\
\hline \multirow[t]{2}{*}{ KENBU } & $\mathrm{a}$ & $\mathrm{a}$ & a & $b$ & $b$ & $\mathrm{~b}$ & $\mathrm{a}$ & $\mathrm{a}$ \\
\hline & $95.3 \pm 4.7$ & $95.7 \pm 2.3$ & $95.3 \pm 2.9$ & $0 \pm 0$ & $0 \pm 0$ & $0 \pm 0$ & $100 \pm 0$ & $100 \pm 0$ \\
\hline
\end{tabular}

*Aynı satırda farklı küçük harflerle gösterilen ortalamalar Duncan Çoklu Karşılaştırma Testine göre ( $P \leq 0.05)$ önem seviyesinde birbirinden farklıdır. TEP:Tepraloxydim, QUI: Quizalofop, PEN: Pendimethalin, OXY: Oxyfluorfen, BEN:Bentazone, LIN: Linuron

Ancak, geniş yapraklı yabancı otlara karşı herhangi bir etki görülmemiştir.

Quizalofop-P-ethyl $50 \mathrm{~g} / \mathrm{l}$, her iki yılda ve iki yılın ortalamasında AVEST (\% 95.3 \pm 2.9 , \% 91.7 \pm 1.7 ve $\%$ 93.5 \pm 1.7 ), ALOMY (\% $90.7 \pm 3.4, \% 90.7 \pm 0.7$ ve $\%$ $90.7 \pm 1.9$ ) ve KENBU (\% 95.7 $\pm 2.3, \% 95.3 \pm 2.6$ ve $\%$ 95.5 \pm 2.0$)^{\prime}$ ya karşı \% 90.0'ın üzerine etki gösterirken PHABR $\quad(\% 81.7 \pm 6.0, \% 79.7 \pm 3.2 \text { ve } \% 80.7 \pm 4.6)^{\prime}$ a karşı \% 79.7 - \% 81.7 arasında etkili bulunmuştur. Ayrıca, Tepraloxydim'de olduğu gibi geniş yapraklı yabancı otlara karşı herhangi bir etki görülmemiştir.

Bentazone $480 \mathrm{~g} / \mathrm{l}$, SINAR (\% 90.3 \pm 2.2 , \% 90.7 \pm 2.3 ve \% 90.5 \pm 1.6$)$, SONOL ( $\% 95.3 \pm 2.9, \% 90.3 \pm 3.2$ ve $\%$ $92.8 \pm 1.7)$, ANAAR (\% $95.3 \pm 2.9$, \% $90.7 \pm 2.3$ ve $\%$ 93.0 \pm 2.3 ), CAPBU (\% $95.3 \pm 0.4, \% 91.7 \pm 1.7$ ve $\%$ 93.5 \pm 0.8 ), VERHE (\% 95.3 $\pm 2.9, \% 91.7 \pm 1.7$ ve $\% 93.5 \pm 1.8$ ) ve STEME (\% 90.3 $\pm 0.3, \% 91.7 \pm 1.7$ ve $\% 91.0 \pm 0.8$ )'e karşı \% 90'ın üzerinde etki göstermiştir. CHEAL (\% 90.3 $\pm 2.6, \%$
$85.3 \pm 2.9$ ve $\% 87.8 \pm 0.2$ ), LAMAM (\% $90.3 \pm 1.5, \%$ $86.7 \pm 3.3$ ve $\% 88.5 \pm 1.9$ ) ve SLYMA (\% $86.3 \pm 3.3$, \% $81.7 \pm 4.4$ ve $\% 84.0 \pm 1.3$ )'a karşı $\% 80$ 'in üzerinde etki göstermiştir. ANTAR ( $\% 71.7 \pm 6.0, \% \quad 66.7 \pm 4.4$ ve $\%$ $69.0 \pm 1.7$ ) ve RAPRA ( $\% 71.7 \pm 3.3, \% 61.7 \pm 6.0$ ve $\%$ $66.7 \pm 4.6)$ ise \% 70'in üzerinde etki göstermiştir. AVEST, ALOMY, PHABR ve KENBU'ya ise her iki yılda ve iki yılın ortalamasında karşı herhangi bir etki saptanmamıştır.

Oxyfluorfen $480 \mathrm{~g} / \mathrm{l}$, ANAAR (\% 96.7 $\pm 1.7, \% 90.0 \pm 1.2$ ve $\%$ 93.3 \pm 2.7 ), CAPBU (\% 90.3 $\pm 2.9, \% 93.7 \pm 1.9$ ve $\%$ $92.0 \pm 0.8)$, SONOL $(\% 90.3 \pm 2.8, \% 90.0 \pm 2.9$ ve $\% 90.2 \pm 2.7)$, VERHE (\% 95.3 $\pm 1.5, \% 91.7 \pm 2.0$ ve $\% 93.5 \pm 0.3)$ ve LAMAM (\% 90.7 \pm 2.3 , \% 90.0 \pm 2.9 ve $\% 90.3 \pm 2.9$ )'a karş।

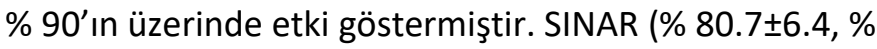
$85.0 \pm 2.9$ ve $\% 82.8 \pm 3.6)$ ve CHEAL (\% 85.3 \pm 4.8 , \% $85.0 \pm 2.9$ ve $\% 85.2 \pm 1.1$ )'a karşı $\% 80$ 'in üzerinde etki göstermiştir. ANTAR ( $\% 75.0 \pm 2.9$, \% $90.0 \pm 2.9$ ve \% $82.5 \pm 1.4$ ), STEME ( $\% 70.7 \pm 3.5$, \% 75.0 \pm 2.9 ve $\%$ 
$72.8 \pm 1.8$ ) ve RAPRA (\% $75.7 \pm 4.6, \% 73.0 \pm 4.4$ ve $\%$ $74.5 \pm 3.8)^{\prime}$ a karşı \% 70'in üzerinde etki göstermiştir. SLYMA ise (\% 65.0 $\pm 5.1, \% 73.3 \pm 4.4$ ve $\% 69.2 \pm 4.8) \quad \%$ 60'ın üzerinde etki göstermiştir. AVEST, ALOMY, PHABR ve KENBU'ya ise her iki yılda ve iki yılın ortalamasında karşı herhangi bir etki saptanmamıştır.

Çizelge 3. Hatay soğan alanlarında yabancı ot mücadele yöntemlerinin etkileri (\%) (2016)

\begin{tabular}{|c|c|c|c|c|c|c|c|c|}
\hline \multirow[t]{2}{*}{ Yabancı Otlar } & \multicolumn{8}{|c|}{ Uygulamalar } \\
\hline & TEP & QUI & PEN & OXY & BEN & LiN & ÇAPA & ÇAPA+LIN \\
\hline \multirow[t]{2}{*}{ ANAAR } & $c^{*}$ & C & $b$ & $\mathrm{~b}$ & $b$ & $\mathrm{~b}$ & $a$ & $b$ \\
\hline & $0 \pm 0$ & $0 \pm 0$ & $90.0 \pm 1.2$ & $90.0 \pm 1.2$ & $90.7 \pm 2.3$ & $90.0 \pm 2.9$ & $100 \pm 0$ & $94.7 \pm 2.4$ \\
\hline \multirow[t]{2}{*}{ ANTAR } & $c$ & $\mathrm{c}$ & $b$ & $b$ & $b$ & $b$ & a & $\mathrm{a}$ \\
\hline & $0 \pm 0$ & $0 \pm 0$ & $80.0 \pm 2.9$ & $90.0 \pm 2.9$ & $66.7 \pm 4.4$ & $84.3 \pm 2.3$ & $100 \pm 0$ & $100 \pm 0$ \\
\hline \multirow[t]{2}{*}{ CAPBU } & $\mathrm{e}$ & $\mathrm{e}$ & c & $b$ & $d$ & $\mathrm{bc}$ & a & $\mathrm{a}$ \\
\hline & $0 \pm 0$ & $0 \pm 0$ & $90.0 \pm 2.7$ & $93.7 \pm 1.9$ & $91.7 \pm 1.7$ & $91.0 \pm 1.0$ & $100 \pm 0$ & $100 \pm 0$ \\
\hline \multirow[t]{2}{*}{ CHEAL } & $d$ & $d$ & c & bc & bc & c & $b$ & a \\
\hline & $0 \pm 0$ & $0 \pm 0$ & $80.3 \pm 3.2$ & $85.0 \pm 2.9$ & $85.3 \pm 2.9$ & $80.0 \pm 5.8$ & $90.3 \pm 2.9$ & $100 \pm 0$ \\
\hline \multirow[t]{2}{*}{ LAMAM } & c & c & $b$ & $\mathrm{~b}$ & $b$ & $b$ & a & a \\
\hline & $0 \pm 0$ & $0 \pm 0$ & $86.0 \pm 3.1$ & $90.0 \pm 2.9$ & $86.7 \pm 3.3$ & $91.0 \pm 1.5$ & $100 \pm 0$ & $100 \pm 0$ \\
\hline \multirow[t]{2}{*}{ RAPRA } & $\mathrm{e}$ & $\mathrm{e}$ & c & C & $d$ & $b$ & a & a \\
\hline & $0 \pm 0$ & $0 \pm 0$ & $76.7 \pm 4.4$ & $73.3 \pm 4.4$ & $61.7 \pm 6.0$ & $86.7 \pm 1.7$ & $100 \pm 0$ & $100 \pm 0$ \\
\hline \multirow[t]{2}{*}{ SINAR } & $c$ & $\mathrm{c}$ & $a b$ & $b$ & $a b$ & $a b$ & $a b$ & $\mathrm{a}$ \\
\hline & $0 \pm 0$ & $0 \pm 0$ & $90.7 \pm 2.9$ & $85.0 \pm 2.9$ & $90.7 \pm 2.3$ & $90.0 \pm 5.0$ & $91.7 \pm 3.3$ & $94.7 \pm 2.0$ \\
\hline \multirow[t]{2}{*}{ SLYMA } & $c$ & $c$ & $b$ & $b$ & $b$ & $b$ & a & $a$ \\
\hline & $0 \pm 0$ & $0 \pm 0$ & $81.7 \pm 3.3$ & $73.3 \pm 4.4$ & $81.7 \pm 4.4$ & $80.3 \pm 3.2$ & $91.0 \pm 2.1$ & $91.7 \pm 1.7$ \\
\hline \multirow[t]{2}{*}{ SONOL } & $\mathrm{e}$ & $\mathrm{e}$ & $\mathrm{cd}$ & $\mathrm{bc}$ & $\mathrm{bc}$ & $d$ & $a b$ & $a$ \\
\hline & $0 \pm 0$ & $0 \pm 0$ & $85.0 \pm 2.9$ & $90.0 \pm 2.9$ & $90.3 \pm 3.2$ & $81.7 \pm 3.3$ & $94.3 \pm 2.3$ & $100 \pm 0$ \\
\hline \multirow[t]{2}{*}{ STEME } & $\mathrm{e}$ & $\mathrm{e}$ & c & $d$ & $b$ & $c$ & a & $a$ \\
\hline & $0 \pm 0$ & $0 \pm 0$ & $84.7 \pm 3.5$ & $75.0 \pm 2.9$ & $91.7 \pm 1.7$ & $85.3 \pm 2.9$ & $100 \pm 0$ & $100 \pm 0$ \\
\hline \multirow[t]{2}{*}{ VERHE } & $d$ & $d$ & c & $b$ & $b$ & $b$ & a & $a$ \\
\hline & $0 \pm 0$ & $0 \pm 0$ & $82.7 \pm 3.9$ & $91.7 \pm 2.0$ & $91.7 \pm 1.7$ & $90.7 \pm 2.9$ & $100 \pm 0$ & $100 \pm 0$ \\
\hline \multirow[t]{2}{*}{ ALOMY } & $b$ & $b$ & $c$ & $d$ & $d$ & $d$ & $b$ & $a$ \\
\hline & $90.3 \pm 0.3$ & $90.7 \pm 0.7$ & $84.3 \pm 2.3$ & $0 \pm 0$ & $0 \pm 0$ & $0 \pm 0$ & $91.7 \pm 1.7$ & $95.3 \pm 1.5$ \\
\hline \multirow[t]{2}{*}{ AVEST } & $\mathrm{a}$ & $\mathrm{a}$ & $b$ & c & c & $c$ & a & $\mathrm{a}$ \\
\hline & $95.7 \pm 2.3$ & $91.7 \pm 1.7$ & $83.3 \pm 4.4$ & $0 \pm 0$ & $0 \pm 0$ & $0 \pm 0$ & $93.3 \pm 1.7$ & $94.3 \pm 0.7$ \\
\hline \multirow[t]{2}{*}{ PHABR } & $b$ & $b$ & c & $d$ & $\mathrm{~d}$ & $\mathrm{~d}$ & a & $\mathrm{a}$ \\
\hline & $80.3 \pm 3.2$ & $79.7 \pm 3.2$ & $71.7 \pm 3.3$ & $0 \pm 0$ & $0 \pm 0$ & $0 \pm 0$ & $93.3 \pm 1.7$ & $90.0 \pm 2.9$ \\
\hline \multirow[t]{2}{*}{ KENBU } & $b$ & $b$ & $b$ & $c$ & c & $c$ & a & $a$ \\
\hline & $95.3 \pm 2.9$ & $95.3 \pm 2.6$ & $90.7 \pm 4.3$ & $0 \pm 0$ & $0 \pm 0$ & $0 \pm 0$ & $100 \pm 0$ & $100 \pm 0$ \\
\hline
\end{tabular}

*Aynı satırda farklı küçük harflerle gösterilen ortalamalar Duncan Çoklu Karşılaştırma Testine göre $(P \leq 0.05)$ önem seviyesinde birbirinden farklıdır. TEP:Tepraloxydim, QUI: Quizalofop, PEN: Pendimethalin, OXY: Oxyfluorfen, BEN:Bentazone, LIN: Linuron

Linuron $47.5 \mathrm{~g} / \mathrm{l}$, SINAR (\% 90.3 $\pm 3.2, \% 90.0 \pm 5.0$ ve \% $90.2 \pm 4.1)$,ANAAR $(\% 90.3 \pm 2.6, \% 90.0 \pm 2.3$ ve $\% 90.2 \pm 0.2)$, CAPBU (\% 91.3 $\pm 2.0, \% 90.0 \pm 1.0$ ve $\% 91.1 \pm 1.5)$, VERHE (\% $95.3 \pm 0.3, \% 90.7 \pm 2.9$ ve $\% 93.0 \pm 1.3$ ) ve LAMAM (\%

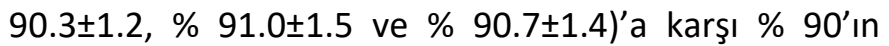
üzerinde etki göstermiştir. SONOL $(\% \quad 85.3 \pm 2.6$, \% $81.7 \pm 3.3$ ve $\% 83.5 \pm 2.8$ ), CHEAL ( $\% 85.7 \pm 3.5$, $\% 91.0 \pm 5.8$ ve $\% 82.8 \pm 1.2$ ), STEME (\% $85.3 \pm 1.2, \% 85.3 \pm 2.9$ ve $\%$ $85.3 \pm 3.7$ ), SLYMA (\% $81.0 \pm 3.8, \% 80.3 \pm 3.2$ ve $\%$ $80.7 \pm 3.7$ ), ANTAR (\% $85.0 \pm 2.9, \% 84.3 \pm 2.3$ ve $\%$ $84.7 \pm 2.2)$ ve RAPRA (\% 85.0 $\pm 5.0, \% 86.7 \pm 1.07$ ve $\%$ $85.8 \pm 3.0$ ) ise $\% 80$ 'in üzerinde etki göstermiştir. AVEST, ALOMY, PHABR ve KENBU'ya ise her iki yılda ve iki yılın ortalamasında karşı herhangi bir etki saptanmamıştır.
Linuron $47.5 \mathrm{~g} / \mathrm{I}+$ Çapa, SINAR (\% 94.7 \pm 3.5 , \% 94.7 \pm 2.0 ve $\% 94.7 \pm 2.2$ ), SONOL ( $\% 91.3 \pm 2.4$, $\% 100 \pm 0$ ve $\%$ $95.7 \pm 1.2$ ), ANAAR (\% $100 \pm 0, \% 94.7 \pm 2.4$ ve $\% 97.3 \pm 1.2$ ), CAPBU (\% $100 \pm 0, \% 100 \pm 0$ ve $\% 100 \pm$ ), VERHE (\% 100 \pm , $\% 100 \pm 0$ ve $\% 100 \pm 0$ ), STEME (\% $100 \pm 0, \% 100 \pm 0$ ve $\%$ $100 \pm 0$ ), CHEAL (\% 95.3 $\pm 2.9, \% 100 \pm 0$ ve $\% 97.7 \pm 1.5$ ), LAMAM (\% 95.3 \pm 2.6 , \% $100 \pm 0$ ve $\% 97.7 \pm 1.3$ ), SLYMA (\% $90.0 \pm 2.7, \% 91.7 \pm 1.7$ ve $\% 90.8 \pm 1.7$ ), ANTAR ( $\% 100 \pm 0$, $\%$ $100 \pm 0$ ve $\% 100 \pm 0$ ), RAPRA ( $\% 100 \pm 0, \% 100 \pm 0$ ve $\%$ $100 \pm 0$ ), AVEST (\% 90.7 $\pm 2.9, \% 94.3 \pm 0.7$ ve $\% 92.5 \pm 1.6)$, ALOMY (\% 95.7 $\pm 2.3, \% 95.3 \pm 1.5$ ve $\% 95.5 \pm 1.0$ ), PHABR (\% $90.3 \pm 1.5, \% 90.0 \pm 2.9$ ve $\% 90.7 \pm 1.2$ ) ve KENBU (\% $100 \pm 0, \% 100 \pm 0$ ve $\% 100 \pm 0$ )'ya her iki yılda ve iki yılın ortalamasında da \% 90'ın üzerinde etki göstermiştir. 
Çizelge 4. Hatay soğan alanlarında yabancı ot mücadele yöntemlerinin ortalama etkileri (\%) (2015 ve 2016$)$

\begin{tabular}{|c|c|c|c|c|c|c|c|c|}
\hline \multirow[t]{2}{*}{ Yabancı Otlar } & \multicolumn{8}{|c|}{ Uygulamalar } \\
\hline & TEP & QUI & PEN & OXY & BEN & LiN & ÇAPA & ÇAPA+LIN \\
\hline \multirow[t]{2}{*}{ ANAAR } & $\mathrm{c}^{*}$ & $\mathrm{c}$ & $b$ & $b$ & $b$ & $b$ & $a$ & $a$ \\
\hline & $0 \pm 0$ & $0 \pm 0$ & $90.2 \pm 1.6$ & $93.3 \pm 1.0$ & $93.0 \pm 2.3$ & $90.2 \pm 0.2$ & $97.7 \pm 1.5$ & $97.3 \pm 1.2$ \\
\hline \multirow{2}{*}{ ANTAR } & c & c & $b$ & $b$ & $b$ & $b$ & $\mathrm{a}$ & a \\
\hline & $0 \pm 0$ & $0 \pm 0$ & $80.5 \pm 2.8$ & $82.5 \pm 1.4$ & $69.2 \pm 1.7$ & $84.7 \pm 2.2$ & $100 \pm 0$ & $100 \pm 0$ \\
\hline \multirow[t]{2}{*}{ CAPBU } & $d$ & $d$ & C & bc & $b$ & bc & $\mathrm{a}$ & $\mathrm{a}$ \\
\hline & $0 \pm 0$ & $0 \pm 0$ & $90.3 \pm 1.4$ & $92.0 \pm 0.8$ & $93.5 \pm 0.8$ & $91.1 \pm 1.5$ & $100 \pm 0$ & $100 \pm 0$ \\
\hline \multirow[t]{2}{*}{ CHEAL } & $\mathrm{e}$ & $\mathrm{e}$ & $\mathrm{d}$ & $\mathrm{cd}$ & $\mathrm{bc}$ & $d$ & $b$ & $\mathrm{a}$ \\
\hline & $0 \pm 0$ & $0 \pm 0$ & $82.8 \pm 2.7$ & $85.2 \pm 1.1$ & $87.8 \pm 0.2$ & $82.8 \pm 1.2$ & $91.5 \pm 1.3$ & $97.7 \pm 1.5$ \\
\hline \multirow[t]{2}{*}{ LAMAM } & c & $\mathrm{c}$ & $b$ & $b$ & $b$ & $b$ & $\mathrm{a}$ & a \\
\hline & $0 \pm 0$ & $0 \pm 0$ & $85.7 \pm 2.9$ & $90.3 \pm 1.2$ & $88.5 \pm 1.9$ & $90.7 \pm 1.4$ & $97.5 \pm 1.4$ & $97.7 \pm 1.3$ \\
\hline \multirow[t]{2}{*}{ RAPRA } & C & c & $b$ & $b$ & $b$ & $b$ & a & a \\
\hline & $0 \pm 0$ & $0 \pm 0$ & $81.2 \pm 3.2$ & $74.5 \pm 3.8$ & $66.7 \pm 4.6$ & $85.8 \pm 3.0$ & $100 \pm 0$ & $100 \pm 0$ \\
\hline \multirow[t]{2}{*}{ SINAR } & $\mathrm{c}$ & $\mathrm{c}$ & $a b$ & $b$ & $a b$ & $a b$ & $\mathrm{a}$ & $\mathrm{a}$ \\
\hline & $0 \pm 0$ & $0 \pm 0$ & $90.5 \pm 1.3$ & $82.8 \pm 3.6$ & $90.5 \pm 1.6$ & $90.2 \pm 4.1$ & $93.5 \pm 3.1$ & $94.7 \pm 2.2$ \\
\hline \multirow[t]{2}{*}{ SLYMA } & $\mathrm{d}$ & $d$ & $b$ & $c$ & $b$ & $b$ & $\mathrm{a}$ & $\mathrm{a}$ \\
\hline & $0 \pm 0$ & $0 \pm 0$ & $81.0 \pm 0.8$ & $69.2 \pm 4.8$ & $84.0 \pm 1.3$ & $80.7 \pm 3.7$ & $91.3 \pm 1.2$ & $90.8 \pm 1.7$ \\
\hline \multirow[t]{2}{*}{ SONOL } & $\mathrm{d}$ & $d$ & bc & $a b$ & a & c & a & $a$ \\
\hline & $0 \pm 0$ & $0 \pm 0$ & $85.2 \pm 2.9$ & $90.2 \pm 2.7$ & $92.8 \pm 1.7$ & $83.5 \pm 2.8$ & $92.5 \pm 2.3$ & $95.7 \pm 1.2$ \\
\hline \multirow[t]{2}{*}{ STEME } & $\mathrm{e}$ & $\mathrm{e}$ & $\mathrm{bc}$ & d & $\mathrm{b}$ & $\mathrm{c}$ & $\mathrm{a}$ & $a$ \\
\hline & $0 \pm 0$ & $0 \pm 0$ & $87.5 \pm 1.8$ & $72.8 \pm 0.3$ & $91.0 \pm 0.8$ & $85.3 \pm 3.7$ & $100 \pm 0$ & $100 \pm 0$ \\
\hline \multirow[t]{2}{*}{ VERHE } & $\mathrm{d}$ & $d$ & $c$ & $b$ & $b$ & $b$ & $\mathrm{a}$ & a \\
\hline & $0 \pm 0$ & $0 \pm 0$ & $86.5 \pm 2.0$ & $93.5 \pm 0.3$ & $93.5 \pm 1.8$ & $93.0 \pm 1.3$ & $100 \pm 0$ & $100 \pm 0$ \\
\hline \multirow[t]{2}{*}{ ALOMY } & $a b$ & $b$ & $b$ & $c$ & c & c & $a b$ & $a$ \\
\hline & $91.8 \pm 2.3$ & $90.7 \pm 1.9$ & $87.5 \pm 1.3$ & $0 \pm 0$ & $0 \pm 0$ & $0 \pm 0$ & $91.7 \pm 1.7$ & $95.5 \pm 1.0$ \\
\hline \multirow[t]{2}{*}{ AVEST } & a & $\mathrm{a}$ & $b$ & $\mathrm{C}$ & c & c & $\mathrm{a}$ & a \\
\hline & $93.5 \pm 1.8$ & $93.5 \pm 1.7$ & $86.8 \pm 1.9$ & $0 \pm 0$ & $0 \pm 0$ & $0 \pm 0$ & $94.3 \pm 2.7$ & $92.5 \pm 1.3$ \\
\hline \multirow[t]{2}{*}{ PHABR } & bc & $c$ & c & $d$ & $d$ & $d$ & $\mathrm{a}$ & $a b$ \\
\hline & $83.0 \pm 1.6$ & $80.7 \pm 4.6$ & $76.0 \pm 5.6$ & $0 \pm 0$ & $0 \pm 0$ & $0 \pm 0$ & $94.3 \pm 0.7$ & $90.7 \pm 1.2$ \\
\hline \multirow[t]{2}{*}{ KENBU } & $a b$ & $a b$ & $b$ & $\mathrm{c}$ & c & c & $\mathrm{a}$ & a \\
\hline & $95.3 \pm 2.6$ & $95.5 \pm 2.0$ & $93.0 \pm 2.5$ & $0 \pm 0$ & $0 \pm 0$ & $0 \pm 0$ & $100 \pm 0$ & $100 \pm 0$ \\
\hline
\end{tabular}

*Aynı satırda farklı küçük harflerle gösterilen ortalamalar Duncan Çoklu Karşılaştırma Testine göre $(P \leq 0.05)$ önem seviyesinde birbirinden farklıdır. TEP:Tepraloxydim, QUI: Quizalofop, PEN: Pendimethalin, OXY: Oxyfluorfen, BEN:Bentazone, LIN: Linuron

Çapa, SINAR (\% 95.3 $\pm 2.9, \% 91.7 \pm 3.3$ ve \% 93.5 \pm 3.1 ), SONOL (\% 90.7 $\pm 2.6, \% 94.3 \pm 2.3$ ve $\% 92.5 \pm 2.3$ ), ANAAR (\% 95.3 $\pm 2.9, \% 100 \pm 0$ ve $\% 97.7 \pm 1.5)$, CAPBU (\% 100 \pm 0 , $\% 100 \pm 0$ ve $\% 100 \pm 0$ ), VERHE (\% $100 \pm 0, \% 100 \pm 0$ ve $\% 100 \pm 0)$, STEME (\% $100 \pm 0$, $\% 100 \pm 0$ ve $\% 100 \pm 0)$, CHEAL (\% 92.7 $\pm 1.5, \% 90.3 \pm 2.9$ ve $\% 91.5 \pm 1.3$ ), LAMAM (\% 95.0 $\pm 2.9, \% 100 \pm 0$ ve $\% 97.5 \pm 1.4$ ), SLYMA (\% $91.7 \pm 1.7, \% 91.0 \pm 2.1$ ve $\% 91.3 \pm 1.2$ ), ANTAR (\% 100 $\pm \%$ $100 \pm$ ve $\% 100 \pm 0)$, RAPRA ( $\% 100 \pm 0, \% 100 \pm 0$ ve \% $100 \pm 0$ ), AVEST (\% 95.3 $\pm 3.7, \% 93.3 \pm 1.7$ ve $\% 94.3 \pm 2.7$ ), ALOMY (\% 91.7 $\pm 4.4, \% 91.7 \pm 1.7$ ve $\% 91.7 \pm 1.7$ ), PHABR (\% 95.3 $\pm 2.6, \% 93.3 \pm 1.7$ ve $\% 94.3 \pm 0.7$ ) ve KENBU (\% $100 \pm 0, \% 100 \pm 0$ ve $\% 100 \pm 0$ )'ya her iki yılda ve iki yılın ortalamasında da \% 90'ın üzerinde etki göstermiştir.

Kırıkhan ilçesinde 2015 ve 2016 yıllarında soğan tarlalarında bulunan yabancı otlara karşı yapılan herbisit uygulamalarının, mekanik mücadelenin ve kimyasal + mekanik mücadelenin verime olan etkileri ve iki yılın ortalamaları, sırasıyla; Pendimethalin $450 \mathrm{~g} / \mathrm{l}$ uygulamasında $\quad(3809.2 \pm 384.6, \quad 3130.4 \pm 709.2$ ve $3469.8 \pm 188.8 \mathrm{~kg} / \mathrm{da})$, Tepraloxydim $45 \mathrm{~g} / \mathrm{l}$ uygulamasında $\quad(3384,7 \pm 18.3, \quad 2575,3 \pm 216.3$ ve $2979,9 \pm 107.5 \mathrm{~kg} / \mathrm{da}$ ), Quizalofop-P-ethyl $50 \mathrm{~g} / \mathrm{l}$ uygulamasında $(3501.6 \pm 66.9, \quad 2286.5 \pm 297.3$ ve $2894.1 \pm 148.5 \mathrm{~kg} / \mathrm{da}$ ), Bentazone $480 \mathrm{~g} / \mathrm{l}$ uygulamasında $(3625.7 \pm 285.6,2860.4 \pm 155.7$ ve $3243.0 \pm 94.7 \mathrm{~kg} / \mathrm{da})$, Oxyfluorfen $480 \mathrm{~g} / \mathrm{l}$ uygulamasında $(3961.9 \pm 228.1$, $3738.2 \pm 91.6$ ve $3850.0 \pm 186.4 \mathrm{~kg} / \mathrm{da}$ ), Linuron $47.5 \mathrm{~g} / \mathrm{l}$ uygulamasında $\quad(4046.1 \pm 278.4, \quad 3081.8 \pm 107.4$ ve $3563.9 \pm 177.0 \mathrm{~kg} / \mathrm{da}$ ), Linuron $47.5 \mathrm{~g} / \mathrm{l}$ + Çapa uygulamasında $\quad(4457.1 \pm 315.7, \quad 3981.9 \pm 262.9$ ve $4219.4 \pm 201.3 \mathrm{~kg} / \mathrm{da})$, Çapa uygulamasında (43564 \pm 86.0 , $4078.9 \pm 239.3$ ve $4217.7 \pm 126.6 \mathrm{~kg} / \mathrm{da}$ ) ve Kontrolda $(2206.9 \pm 407.6,2155.3 \pm 17.9$ ve $2181.1 \pm 208.5 \mathrm{~kg} / \mathrm{da})$. Yabancı otlara karşı herbisitlerin etkileri ve soğan verim değerleri genel olarak incelendiğinde 2014-2015 ve 
2015-2016 yılları ortalamasından elde edilen en yüksek etkiler Çapa + Linuron ve Çapa uygulamalarından elde edilmiştir. Bu sonuçlar parsellerden elde edilen soğan verim değerleri tarafından da desteklenmektedir.

Uygulamaların 2015 ve 2016 yılındaki soğan verimine etkisine bakıldığında, 2015 yılındaki en düşük verim kontrol parselinde (2206.9 \pm 407.6$)$, en yüksek verim ise

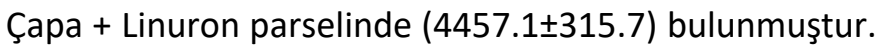
2016 yılındaki en düşük verim 2015 yılında olduğu gibi kontrol parselinde (2155.3 \pm 17.9$)$, en yüksek verim ise Çapa parselinde (4078.9 \pm 239.3$)$ bulunmuştur.

Uygulamaların 2015 ve 2016 yılı ortalamalarının soğan verimine etkisine bakıldığında, en düşük verim kontrol parselinde $(2181.1 \pm 208.5)$, en yüksek verim ise Çapa + Linuron parselinde (4219.4 \pm 201.3$)$ bulunmuştur.

Soğan alanlarında kullanılan yöntemlerden Çapa ve Çapa + Linuron uygulamaları Parsellerde mevcut yabancı otlar üzerine yüksek etki göstermiştir. Bu beklenen bir sonuç olup, yapılan uygulamalarda deneme alanındaki hem dar yapraklı hem de geniş yapraklı yabancı otlar kontrol edilmiştir. Bu başarılı uygulamaların sonucunun özellikle elde edilen soğan verimine yansıdığı görülmektedir. Çünkü en yüksek verimler bu parsellerden alınmıştır.

Dar yapraklı yabancı ot ilaçları (Tepraloxydim ve Quizalofop) etki alanındaki yabancı otları ve kendi gelen buğdayı yüksek oranda kontrol etmiş ancak bunun verime yansıması daha az oranda olmuştur, bunun nedeninin herbisitlerden ziyade parsellerdeki yabancı otların tür ve yoğunluğundan kaynaklandığı düşünülmektedir. Parsellerde geniş yapraklı yabancı otların daha yüksek yoğunlukta bulunması nedeniyle mevcut dar yapraklı yabancı otlar kontrol edilmesine rağmen bunun verime yansıması daha düşük düzeyde kalmıştır. $\mathrm{Bu}$ nedenle mücadele programlarının düzenlenmesinde mevcut yabancı ot varlığına dikkat edilmesinin önemi ortadadır. Dolayısı ile böyle yabancı ot dağılımının olduğu alanlarda dar yapraklı yabancı ot ilaçları ile birlikte geniş yapraklı yabancı ot ilaçları ve/veya mekanik mücadele ile desteklenmesi gerekmektedir.

Oxyfluorfen uygulama parsellerinde soğan yapraklarındaki hafif sarama ve gelişme geriliği şeklinde görülen fitotoksisite zaman içerisinde kaybolmuş olup soğanlarda ölüm saptanmamıştır. $\mathrm{Bu}$ şekildeki fitotoksisite üreticilerle yapılan görüşmeler sırasında da sık sık dile getirilmektedir. Bunlara rağmen yine de mücadelede başarılı bir sonuç alındığı düşünülmektedir. Elde edilen bu sonuçlar Babiker ve Ahmet (1986), Umeda ve ark. (1999) ve Gürbüz (2007) tarafından desteklenmektedir. Ayrıca, Webber ve Shrefler (2003), Ghosheh (2004) ve Qasem (2006)'in yaptıkları çalışmalar sonucunda elde ettikleri sonuçlar ile benzerlik görülmektedir. Bu konuda Westra ve ark. (1990) özellikle soğanın 2-3 yaprak döneminden sonra yapılan uygulamalarda soğandaki fitotoksisitenin öneminin azaldığını bildirmektedirler.

Yabancı otlarla mücadelede özellikle Çapa ve Çapa + Linuron uygulamaları ön plana çıkmakta bu parsellerdeki yabancı ot mücadelesinde yüksek etki edildiği ve yüksek verim alındığı bu sonuçların diğer sonuçlardan istatistiki olarak da ayrıldığı görülmektedir. Bu beklenen bir sonuç olarak kabul edilmektedir parsellerdeki hem dar hem de geniş yapraklı yabancı otlar düzenli aralıklarla parsellerden uzaklaştırıldığından soğanın gelişimi için uygun bir ortam elde edilmekte bu ise soğan verimine olumlu olarak yansımaktadır. Burada çapanın olabildiğince erken dönemde yapılması dikkat edilmesi gereken önemli bir konu olarak görülmektedir. Çünkü gecikilmesi durumunda yabancı otlar elle çekilirken ve/veya çapalanırken soğana zarar verilebilmektedir. Bu sonuç Kurçman ve ark. (1983), Özdemir (1983), Suleman ve Jamal (2002) tarafından desteklenmektedir. Bu araştırmacılarda benzer konulara dikkat çekmektedirler. Melander ve Hartwing (1997) ve Khokhar ve ark. (2006)'da benzer sonuçları bildirmektedir.

Sonuç olarak soğan alanlarında yabancı otlarla mücadelede parsellerdeki yabancı ot türleri ve yoğunlukları dikkate alınarak mücadele programları yapılmalıdır. Deneme parsellerinde olmamasına rağmen son yıllarda soğan alanlarında küsküt (Cuscuta campestris Yunck.) yaygınlık ve yoğunluklarının artma eğiliminde olduğu gözlenmektedir, bu nedenle bu parazit bitkiye karşı dikkatli olunması gerektiği anlaşılmaktadır. Yabancı ot teşhislerinin doğru yapılarak mücadelede kullanılacak kontrol yöntemi seçilmelidir. Çapalama diğer yöntemlere göre daha yüksek maliyetli olmasına ve zaman zaman uygulanması sırasında soğana zarar verilmesine rağmen yapılacak programlarda öncelik verilmesinin gerektiği düşünülmektedir. Yabancı otların sadece Çapa, Çapa + Linuron uygulamaları hem yabancı otların mücadelesinde iyi sonuç vermekte hem de verim açısından önemli görülmektedir, bu nedenle özellikle işçiliğin ucuz olduğu ve/veya işçilerin kolay temin edildiği yerlerde mekanik mücadele dikkate alınmalı ancak, mücadele yöntemlerinin maliyet hesaplarının yapılmasında yarar görülmektedir. Üreticilerin önemli problemlerinden biri olarak çıkış sonrası uygulanan herbisitlerden kaynaklı etkinlikteki düşük başarı oranı ve soğanda fitotoksisite öne çıkmaktadır. Bu nedenle herbisit uygulamalarının çıkış öncesi herbisitlerinde yer aldığı programlara göre uygulanmasında, ayrıca bu programlar yapılırken mekanik mücadelenin de dikkate alınmasının gerekli olduğu göz ardı edilmemelidir. Mekanik mücadelede 
özellikle derin köklü yabancı otlar çapalanırken veya elle çekilirken soğana verebileceği zarar göz önüne alınarak çok dikkat edilmesi gerekmektedir. Özellikle küsküt bulunan alanlarda küsküt elle çekildikten sonra mutlaka tarladan uzaklaştırılmalıdır. Son olarak, mücadele programlarının Entegre Mücadele ilkeleri ışığında yapılmasının ve uygulanmasının gerekliliği unutulmamalıdır.

\section{ÖZET}

Amaç: Hatay ili soğan üretim alanlarında sorun olan yabancı otlara karşı kimyasal mücadele uygulamaları, mekanik mücadele ve kimyasal + mekanik mücadelenin etkinliklerini belirleme çalışmaları Kırıkhan ilçesinde 2015 ve 2016 yıllarında yapılmıştır.

Yöntem ve Bulgular: Denemeler Tesadüf Blokları deneme deseninde 3 tekerrürlü olarak kurulmuştur. Çalışmada yabancı ot mücadelesi yapılmayan kontrol parselini de içeren 9 uygulama (çıkış öncesi Pendimethalin $450 \mathrm{~g} / \mathrm{l}(300 \mathrm{ml} / \mathrm{da})$, çıkış sonrası Tepraloxydim $45 \mathrm{~g} / \mathrm{l}(100 \mathrm{ml} / \mathrm{da})$, Quizalofop- P-ethyl 50 $\mathrm{g} / \mathrm{l}(100 \mathrm{ml} / \mathrm{da})$, Bentazone $480 \mathrm{~g} / \mathrm{l}(200 \mathrm{ml} / \mathrm{da})$, Oxyfluorfen $480 \mathrm{~g} / \mathrm{l}(40 \mathrm{ml} / \mathrm{da})$, Linuron $47.5 \mathrm{~g} / \mathrm{l}(100$ $\mathrm{ml} / \mathrm{da})$, Linuron $47.5 \mathrm{~g} / \mathrm{l}(100 \mathrm{ml} / \mathrm{da})+$ Çapa ve sadece Çapa) ele alınmıştır.

Genel Yorum: Yabancı otlara karşı herbisitlerin etkileri ve soğan verim değerleri genel olarak incelendiğinde 2015 , 2016 ve 2015-2016 yılları ortalamasından elde edilen en yüksek etkiler Çapa + Linuron ve sadece Çapa uygulamalarından elde edilmiştir.

Çalışmanın Önemi ve Etkisi: Soğanda yabancı otlarla mücadele programı; tarladaki koşullar, yabancı ot türleri ve yoğunlukları dikkate alınarak yapılmalıdır.

Anahtar Kelimeler: Soğan, yabancı ot, kimyasal mücadele, mekanik mücadele.

\section{ÇIKAR ÇATIŞMA BEYANI}

Yazar(lar) çalışma konusunda çıkar çatışmasının olmadığını beyan eder.

\section{ARAŞTIRMACILARIN KATKI ORANI BEYANI}

Yazarlar çalışmaya eşit oranda katkı sağlamış olduklarını beyan eder.

\section{KAYNAKLAR}

Babiker AGT, Ahmed MK (1986) Chemical weed control in transplanted onion (Allium cepa L.) in the Sudan Gezira. Weed Res. 26: 133-138.
Bell CE, Cudney DW, Fennimore SA, Orloff S (2002) Weeds (Ed.: Flint ML). UC IPM Pest Management Guidelines: Onion and Garlic. University of California, Agriculture and Natural Resources, Publication No: 3453, pp 25-34.

Carslon HL, Kirby D (2005) Effect of Herbicide Rate and Application Timing on Weed Control in Dehydrator Onions. University of Florida, Intermountain Research \& Extension Center, Number 115, Florida, USA. pp 1-4.

Derke EC, Dehwe HW, Weber A (1994) Crop Production and Crop Protection. Elsevier, Amsterdam. pp 808.

Ghosheh HZ (2004) Single herbicide treatments for control of broadleaved weeds in onion (Allium cepa). Crop Protect. 23: 539-542.

Günay A (2005) Sebze Yetiştiriciliği, Cilt I, ISBN.97500725-2-9, İzmir. pp 403-417.

Güncan A (2016) Yabancı Otlar ve Mücadele Prensipleri (Güncelleştirilmiş ve İlaveli Altıncı Baskı), Selçuk Üni. Ziraat Fakültesi, Konya. 311s.

Gürbüz R (2007) Çukurova soğan üretim alanlarında görülen yabancı otların öneminin ve bazı herbisitlerin yabancı otlanma ile soğan verimine olan etkilerinin araştırılması. Yüksek Lisans Tezi, Çukurova Üniversitesi, Fen Bil. Ens., Bitki Koruma ABD, 79 s.

Hussain F (1983). Biochemical inhibition (allelopathy) a less understood ecological factor in agroecosystems. Prog. Farm. 3: 33-37.

Kaya H, Üremiş I (2019) Determination of weed species, their frequencies and densities in onion fields in Hatay province. MKU. Tar. Bil. Derg. 24(1) : 21-30.

Khokhar KM, Mahmood T, Shakeel M, Chaudhry MF (2006) Evaluation of integrated weed management practices for onion in Pakistan. Crop Protect. 25: 968972.

Kızılkaya A, Önen H, Özer Z (2001) Soğan verimine yabancı ot rekabetinin etkileri üzerine araştırmalar. Türk. Her. Derg. 4 (2) 58-65.

Kızılkaya A (2003) Tokat ili (Kazova ve Kelkit Vadisi)'nde baş soğan (Allium cepa $\mathrm{L}$.) yetiştirilen alanlarda sorun olan yabancı otlar ve farklı dönemlerde yabancı otların yok edilmesi ile ekonomik eşiğin belirlenmesi. Yüksek Lisans Tezi, Gaziosmanpaşa Üniversitesi, Fen Bil. Ens., Bitki Koruma ABD, 73 s.

Klingman GC, Ashton FM (1982) Weed Science: Principles and Practices (second edition). John Wiley and Sons. pp 449.

Kozan S (1997) Bazı baş soğan çeşitlerinde (Allium cepa L.) tohumdan baş soğan elde edilmesinde tohum ekim zamanının etkileri üzerine araştırmalar. Yüksek Lisans Tezi, Selçuk Üniversitesi, Fen Bil. Ens., Bitki Koruma ABD, $89 \mathrm{~s}$. 
Kurçman M, Taştan B, Erciş A (1983) Orta Anadolu'da karacadan arpacık soğanı yetiştirilen alanlarda sorun oluşturan yabancı otlara karşı ilaçlı mücadele denemeleri. Zirai Müc. Araş. Yı. 18: 122.

Melander B, Hartvig P (1997) Yield responses of weedfree seeded onions (Allium cepa L.) to hoeing close to the row. Crop Protect. 16 (7) 687-691.

Özdemir C, Karasu H, Sönmez S (1983) Marmara Bölgesinde soğanlarda sorun olan yabancı otlarla mücadele olanakları üzerinde araştırmalar. Zirai Müc Araş Yıl 18: 127.

Özer Z, Kadıoğlu i, Önen H, Tursun N (2001) Herboloji (Yabancı Ot Bilimi) (Genişletilmiş 3. Baskı). Gaziosmanpaşa Üni., Ziraat Fakültesi Yayınları, No: 20, Tokat. 403s.

Qasem JR (2006). Chemical weed control in seedbed sown onion (Allium cepa L.). Crop Protect. 25: 618622.

Schwartz HF, Mohan SK (1996) Compendium of Onion and Garlic Diseases, APS Press. pp 54.

Smith R, Fennimore, SA, Orloff S, Poole GJ (2008) Weeds (Ed.: Flint ML). UC IPM Pest Management Guidelines: Onion and Garlic. UC ANR Publication 3453, Oakland, CA. pp 440.

Soylu S, Sertkaya E, Kurt Ş, Üremiş I, Bozkurt IA (2014) Hatay ili Amik ovası soğan (Allium cepa L.) ekim alanlarında görülen önemli hastalık etmenleri, zararlı ve yabancı ot türleri ve yaygınlık durumları. 10 . Sebze Tarımı Sempozyumu Eylül 2-4, Tekirdağ. pp 45.

Suleman M, Jamal M (2002) Evaluation of effective weedycide for onion crop. J. Bio. Sci. 2 (11) 759.

Tepe I (2014) Yabancı Otlarla Mücadele. Sidas Medya Ltd.Şti. Van. 292s.
Uludag A, Uremis I, Arslan M (2018) Biological Weed Control, Non-Chemical Weed Control, (Eds.: Jabran K, Chauhan BS), Academic Press. pp 115-132.

Umeda K, Gal G, Strickland B (1999) Timing of postemergence herbicides for onion weed control. Vegetable Report, University of Arizona, College of Agriculture, USA. pp 1-4.

Uygur FN, Koch W, Walter H (1984) Yabancı Ot Bilimine Giriş (Kurs Notu). PLITS (Plant Protection in the Tropics and Subtropic), 2 (1) Stuttgart, Germany. 114 s.

Van Der Weide RY, Bleeker PO, Achten VTJM, Lotz LAP, Fogelberg F, Melander B (2008) Innovation in mechanical weed control in crop rows. Weed Res. 48 (3) 215-224

Vural H, Eşiyok D, Duman I (2000) Kültür Sebzeleri (Sebze Yetiştirme). Ege Üniversitesi Basımevi, Bornova-İzmir. 440s.

Webber CL, Shrefler J (2003) Weed control options for transplanted onions, Proceedings of the 22nd Annual Horticultural Industry Show, pp 112-115.

Westra P, Pearson CH, Ristau R (1990) Control of venice mallow (Hibiscus trionum) in corn (Zea mays) and onions (Allium cepa). Weed Tech. 4: 500-504.

Yünlü S (2011) Soğan (Allium cepa L.) ve sarımsaktaki (Allium sativum L.) fenolik bileşiklerin HPLC yöntemiyle tayin edilmesi. Yüksek Lisans Tezi, Süleyman Demirel Üniversitesi, Fen Bil. Ens., Bitki Koruma ABD, $101 \mathrm{~s}$.

Zar JH (1996) Biostatistical Analysis (third edition). Prentice Hall, New Jersey, U.S.A. pp 662.

Zimdahl RL (2018) Fundamentals of Weed Science [fifth edition]. Academic Press. pp 758. 